\title{
DA ARTE DE QUEBRAR PEDRAS OU A CENA DA EMANCIPAÇÃO
}

\author{
Edélcio Mostaço
}

\section{Resumo}

Apresentação do pensamento do filósofo Jacques Rancière quanto ao entrecruzamento das dimensões ética, estética e política. Os principais nexos por ele estabelecidos, tais como a partilha do sensível, a emancipação do espectador e a pedagogia libertária são enfocados, visando situar as fontes que constituem seus pontos de partida.

Palavras-chave: sentido do comum, emancipação, ética, estética e política.

\begin{abstract}
Presentation of the thinking of philosopher Jacques Rancière on the intersection of ethical, aesthetic and political dimensions. The main nexus established by him, such as the sharing of the sensitive, the emancipation of the spectator and the libertarian pedagogy are examined in order to locate sources that are their starting points.
\end{abstract}

Keywords: common sense, emancipation, ethics, aesthetics and politics.

Professor emérito de Estética e Política da Universidade Paris VII (Saint Denis), o filósofo Jacques Rancière celebrizou-se internacionalmente como autor de uma obra que entrecruza, com agudo tirocínio e proficientes resultados teóricos, a estética, a ética e a política. Após rastrear os campos da literatura, das artes visuais e do cinema aportou no universo teatral, dedicando seu olhar às formas cênicas em sua última obra publicada: $O$ espectador emancipado..

Apresentar esta obra - opaca, surpreendente, alegoricamente sustentada por raciocínios nunca lineares - é tarefa custosa, é refazer o ziguezague de suas referências, seguir as trilhas que percorreu, transitar entre anáforas e perífrases. Transladar para outra língua os termos, expressões, construções frásicas e vocábulos muitas vezes forjados pelo autor resulta desconcertante, pois implica fazer falar um texto dialógico, no interior do qual nos deslocamos, nos interrogamos, à deriva do que somos frente àquelas

${ }^{1}$ Bolsista de Produtividade e Pesquisa CNPq. Professor Associado na Universidade do Estado de Santa

Catarina, onde leciona Estética na graduação e na pós-graduação. 
formulações, muitas vezes sem equivalentes em nossa língua. Negociação talvez exprima esse paradoxo, que também pode ser designado como permuta ou diplomacia.

Jacques Rancière foi companheiro de Louis Althusser quando das primeiras incursões do seminário sobre O Capital, cujo resultado mais notável foi o livro Para ler O Capital, lançado por Althusser em 1965, um empreendimento que agregou, em torno da mesma mesa de trabalho, alguns jovens que logo alcançaram destaque na cena sociopolítica, tais como Étienne Balibar, Michel Pêcheux, Marta Harnecker, entre outros. Os efeitos do seminário, através de escritos e intervenções, causaram um pequeno terremoto entre as hostes da esquerda tradicional, especialmente o Partido Comunista Francês, adepto do legado stalinista e das renitentes posturas interpretativas vinculadas a um marxismo-leninismo ortodoxo. Aqueles eram tempos em que o estruturalismo tornava-se visível para a sociedade ampla, ganhando destaque na imprensa e nas polêmicas que engrossavam os suplementos culturais, simultâneas às revoltas e contestações que culminaram com o Maio de 1968.

O primeiro livro de Rancière a merecer destaque foi Le philosophe et ses pauvres (O filósofo e seus pobres, 1983), onde juntou artigos de anos anteriores que colocavam em foco algumas noções relevantes, tais como: o que é massa? Quem é a classe trabalhadora? O que é proletariado? O que é ideologia e conhecimento?, sendo este último tópico uma pedra angular dentro das preocupações que irão ocupá-lo ao longo dos anos. O contexto em que se dá o ato de conhecer, fundo indispensável para engendrar a consciência será, ao lado da discussão da democracia, uma das linhas de fuga de seu pensamento.

Em Os nomes da história, sua primeira obra traduzida no Brasil, voltou-se para a crítica do materialismo histórico, em estreita sintonia com a genealogia preconizada por Foucault. Outros nomes com quem sua obra vai encontrar diversas afinidades são os de Gilles Deleuze, Jean-François Lyotard e Jacques Lacan, embora sua visada seja sempre bastante pessoal e inconfundível. Em La nuit des prolétaires. Archives du rêve ouvrier, (A noite dos proletários. Arquivos do sonho operário, 1981), voltou-se para a literatura que circulava entre os extratos sociais mais baixos da população ao longo do século XIX, ali flagrando as conexões entre arte, imaginário, sonho político e utopias a se desenharem junto à ação operária.

Desde os anos de 1990 vêm enfatizando temas concernentes à dimensão artística, e na seara das inter-relações entre estética, ética e política publicou alguns volumes, entre os quais Le partage du sensible (A partilha do sensível, 2000); L'inconscient esthétique (O inconsciente estético, 2001); Malaise dans l'esthetique (Doença na estética, 2004); La haine de la democracie (O ódio 
da democracia, 2005); Moments politiques: interventions 1977-2009 (Momentos políticos: intervenções 1977-2009, 2009) e L'spectateur emancipé (O espectador emancipado, 2009). No Brasil foram lançados, mais recentemente, $O$ mestre ignorante (2004) e A partilha do sensível (2005).

Considerado uma espécie de auto-referência intelectual metafórica ou um meta-texto de pedagogia, $O$ mestre ignorante é uma aguda reflexão sobre a pedagogia, seguindo os passos de um professor de Retórica que, perseguido após seu envolvimento com a Revolução Francesa, refugiou-se nos Países Baixos, onde passou a recrutar alunos para sobreviver de seu ofício. Ocorre que uma dificuldade crucial se anuncia então: ele não sabia holandês nem seus discípulos o francês; dificuldade, afinal, superada através do recurso a uma edição bilíngue de Telêmaco, texto de Fènelon, ponte de ligação entre um e outros e que poderia ensejar o necessário diálogo entre as partes, possibilitando o mútuo aprendizado. O que temos, portanto, não é apenas a aprendizagem de uma nova língua mas, acima de tudo, a necessidade de reaprender significados, de reconsiderar tudo o que se sabia à luz de uma busca de entendimento mais amplo, o que fará do antigo mestre um ignorante de volta às origens. $\mathrm{O}$ ponto de partida foi tomado de fatos que envolveram Joseph Jacotot e diversos outros educadores que partilhavam um mesmo ideário derivado do pensamento societário de Fourier. Há na obra um evidente substrato político, inerente à análise dessa nova postura frente ao aprendizado e à desmontagem de um mito ligado à pedagogia, além dos vínculos urdidos em relação à ética e à estética.

Tais vínculos nunca deixaram de ocupar Rancière. Em A partilha do sensível retoma, agora em viés mais explicitamente sintonizado com o universo das artes, outro atalho primordialmente político, antes anunciado em $O$ desentendimento. Trata-se da consideração do que é comum, aquilo que marca, na convivência social, as divisões entre as vozes - autorizadas ou não, competentes ou não - que se manifestam no âmbito social.

A questão em destaque privilegia os primórdios da consciência política ocidental, as bases sobre as quais foram erigidas as dicotomias de poder de nossas sociedades históricas: quem fala e quem obedece. Para tanto o pensamento de Platão e Aristóteles são revisitados (isto é, a República e a Política), e um agudo equacionamento da mímesis é empreendido com o objetivo de deslindar liames que tanto enovelaram esse conceito axial da estética ocidental a ponto de, na atualidade, uma verdadeira dissecação do mesmo tornar-se indispensável para devolver à inteligência seus sentidos originais.

Em acordo com Platão, a cidade ideal separa o uso da palavra entre os indivíduos segundo suas ocupações: os artesãos, porque ocupados com as 


\section{Urdimento}

${ }^{2}$ Pode ser interessante confrontar-se tais proposições com aquelas desenvolvidas por Nicolas BOURRIAUD relativas ao que denominou estética relacional, práticas artísticas dialógicas surgidas especialmente durante a década de 1990: Estética relacional. São Paulo: Martins Fontes, 2009. mãos durante todo o tempo, podem apenas balbuciar, produzir barulho, não manifestando um raciocínio correto; enquanto os guardiões-filósofo, porque treinados nas estratégias de guerra e dos discursos, são os únicos capazes de falar verdadeiramente, emitindo juízos. Tal teoria encontra desdobramentos no pensamento aristotélico, onde é observado que "todo animal falante é um animal político”, mas o escravo, se é capaz de compreender a linguagem, não a possui, razão pela qual não goza de isonomia na assembléia, como anotado na Política. Desse modo, “a partilha do sensível faz ver quem pode tomar parte no comum em função daquilo que faz, do tempo e do espaço em que essa atividade se exerce. Assim, ter essa ou aquela 'ocupação' define competências ou incompetências para o comum” (p.16). Para Rancière, a estética possui seu fundamento nessa partilha do sensível, naquilo que se vê, no que pode ser visto ou se pode dizer sobre o que é visto, separando os que têm competência para ver e qualidade para dizer, o que implica, igualmente, ter domínio sobre o tempo e o espaço. "È a partir dessa estética primeira que se pode colocar a questão das 'práticas estéticas', no sentido em que as entendemos, isto é, como formas de visibilidade das práticas de arte, do lugar que ocupam, do que ‘fazem' no que diz respeito ao comum”, conclui ele (p. 17). ${ }^{2}$

A condenação platônica das artes - o teatro, em particular - advém, portanto, da

distribuição geral das maneiras de fazer e nas suas relações com as maneiras de ser e formas de visibilidade. Antes de se fundar no conteúdo imoral das fábulas, a proscrição platônica dos poetas funda-se na impossibilidade de se fazer duas coisas ao mesmo tempo. A questão da ficção é, antes de tudo, uma questão da distribuição dos lugares. Do ponto de vista platônico, a cena de teatro, que é simultaneamente espaço de uma atividade pública e lugar de exibição dos 'fantasmas', embaralha a partilha das identidades, atividades e espaços (p. 17).

É através desse liame entre estética e ética que a reconsideração da mímesis volta a brilhar enquanto conceito fisgado da Poética aristotélica, em aberto contraponto às posturas platônicas, uma vez que ela não é um princípio normativo quanto às representações que o artista efetua, mas, antes, um princípio pragmático funcional, um modo das artes poéticas executarem coisas específicas, isto é, imitações/representações. Afirma então:

Tais imitações não se enquadram nem na verificação habitual dos produtos das artes por meio de seu uso, nem na legislação da verdade sobre os discursos e as imagens. Nisto consiste a grande operação efetuada pela elaboração aristotélica da mímesis e pelo privilégio dado à ação trágica. É o feito do poema, a fabricação de 
uma intriga que orquestra ações representando homens agindo, que importa, em detrimento do ser da imagem, cópia interrogada sobre seu modelo (p. 30, grifos do autor).

A mímesis, como explicita o filósofo, "não é a lei que submete as artes à semelhança. É, antes, o vinco na distribuição das maneiras de fazer e das ocupações sociais que torna as artes visíveis. Não é um procedimento artístico, mas um regime de visibilidade das artes. Um regime de visibilidade das artes é, ao mesmo tempo, o que autonomiza as artes, mas também o que articula essa autonomia a uma ordem geral das maneiras de fazer e das ocupações” (p. 32). Decorre então que o estético não é uma teoria da sensibilidade, do gosto ou do prazer, mas um modo de existência de tudo o que é estético, sensível, perceptível ou representável habitando a potência de um pensamento que, pouco a pouco, com o percurso histórico, veio a tornar-se estranho a si mesmo, descolado do entendimento das origens.

Tal descolamento tornar-se-á ainda mais perceptível com o advento da estética moderna, marcada pela miragem proustiana do livro calculado; pela ideia mallarmiana do poema do espectador-poeta; pela prática surrealista da obra exprimindo o inconsciente; atingindo até mesmo a ideia bressoniana do cinema como pensamento do cineasta extraído dos corpos de seus modelos - exemplos de crise que, segundo Rancière, conduziram àquilo que identifica como o estado atual das artes, crivado por aguda perda de historicidade.

Tais crises e esse patamar problemático traz à tona outra dimensão que eu gostaria de destacar, dado o caráter do dossiê que se descortina: a possível interação entre arte e ação política, ou, dito de outro modo, as clivagens existentes entre a arte, o teatro e a resistência.

A noção de resistência não é nova, estando presente desde os arroubos do sturm und drung até as escaramuças que acompanharam a Revolução Francesa e seus desdobramentos; apoiou as empresas que instituíram o realismo e vibrou na pena de Nietzsche; deu lastro aos naturalistas e tornouse aguerrida nos primórdios da Revolução Russa, na República de Weimar, na luta anti-franquista e antinazista, alimentando um sem número de integrantes ligados às vanguardas do começo do século XX. Essa resistência acompanhou os temas que se apresentavam, em cada momento, como obstáculos: os ideais clássicos, a moral burguesa, o positivismo, o domínio econômico das elites, o mercado de arte, até atingir, mais recentemente, as estruturas financeiras, pedagógicas e culturais que sustentam o modo capitalista de produção.

De que resistência se fala? Existem ao menos duas posturas consagradas, aquela da própria arte e aquela dos artistas com ela envolvidos; no 


\section{Urdimento}

${ }^{3}$ RANCIÈRE, Jacques. "Será que a arte resiste à alguma coisa?" In: Daniel Lins, Nietzsche/Deleuze - arte resistência. Rio de Janeiro. Forense Universitária: 2007, pp. 126-140. primeiro caso, em função daquilo que é entendido como arte desde a analítica do belo kantiana, quando ocorreu o deslocamento do sensível para fora do pensamento e a submissão das afecções à busca de um bem, em função da intervenção do desejo; no segundo caso, quando os indivíduos artistas, porque guiados por uma vetorização desse desejo, passam a orientar sua ação contra uma dada ordem de coisas, projetando nesse bem algum conteúdo ideológico ou utópico.

Para Rancière, produziu-se desde então um dissenso em relação ao sensível. Assim:

a experiência estética é a experiência de um sensível duplamente desconectado: desconectado com relação à lei do entendimento que submeteu a percepção sensivel às suas categorias e com relação à lei do desejo que submete nossas afecções à busca de um bem. A forma apreendida pelo julgamento estético não é nem a de um objeto do conhecimento nem a de um objeto do desejo. É esse nem... nem..., que define a experiência do belo como experiência de uma resistência. $O$ belo é o que resiste, ao mesmo tempo, à determinação conceitual e à atração dos bens consumíveis (Será que a arte resiste à alguma coisa?, p. 130). ${ }^{3}$

Se havia, até meados do século XVIII, um acordo em torno da poiesis, inaugurado com a postura aristotélica de coisa comum entre uma natureza produtora e outra receptora - a aisthesis -, conformando aquilo que se consagrou jungir como natureza humana, ocorreu, a partir da analítica kantiana, um dissenso: "se o belo é sem conceito e se toda arte é a operação de ideias que transformam uma matéria, segue-se que o belo e a arte estão em uma relação de disjunção. Os fins que a arte se propõe estão em contradição com a finalidade sem fim que caracteriza a experiência do belo" (p. 131). Foi dado o passo, assim, para que nascesse o gênio que o sturm und drang imortalizará como ideal para o artista criador e que a pena de Hegel consagrará como ideal para o Espírito:

a obra de arte é uma inscrição material de uma diferença para consigo mesma do pensamento: começa pela vibração sublime do pensamento que busca inutilmente sua morada nas pedras da pirâmide, continua no enlace clássico da matéria e de um pensamento que só consegue se realizar nela ao preço da sua própria fraqueza: a religião grega sendo desprovida de interioridade pode, com efeito, exprimir-se idealmente na perfeição da estátua de um deus; enfim, a obra é a linha de fuga da flecha 
gótica que se estende na direção de um céu inacessível e anuncia, assim, o fim em que, o pensamento alcançando enfim sua morada, a arte terá cessado de ser um lugar do pensamento (p. 131-132).

Há um jogo paradoxal aqui, entre o poder da manifestação sensível e aquele da significação da obra de arte, efetivado, na perspectiva hegeliana, como "espírito do povo", esse outro que nos permite ver a estátua grega como resultado estético, quando ela teria sido, em seu tempo, símbolo de devoção ritual, instância do sagrado. Não por outra razão Apolo e Dioniso encarnarão, sob os auspícios de Nietzsche, os mais claros opostos frutos daquele aludido dissenso. Fora Schiller, porém, quem operara a decisiva leitura política desse dissenso, na esteira dos desdobramentos da Revolução Francesa: ao enfatizar o livre jogo estético propiciado pela arte e a universalidade do juízo de gosto, definiu uma liberdade e uma igualdade sem precedentes. Postulou uma "nova arte de viver", romântica e revolucionária, em oposição àquela clássica e nobiliárquica, augurando mesmo uma nova humanidade por vir, uma nova comunidade entre homens iguais - cujos fundamentos repousam numa educação estética do homem.

Para muitos artistas ficaram estabelecidos, desde então, os fundamentos para o encontro de uma função social para a arte, assim como um programa de ação individual e coletiva que passou a orientar, desde os primórdios da modernidade, o percurso de um sem número de artistas e de movimentos estéticos. Na esteira desse "povo livre" não há divórcio nas experiências estéticas advindas com a política, a arte ou a religião: o que a arte promete é um futuro onde não mais esteja apartada das instâncias socioculturais e de crença. "A 'resistência' da arte promete um povo na medida em que promete sua própria abolição, a abolição da distância ou da inumanidade na arte" (p. 135), destaca Rancière, para então rematar: "Da Revolução Francesa à Revolução Soviética, a revolução estética significou essa auto-realização e essa autosupressão da arte na construção de uma nova vida, na qual a arte, a política, a economia ou a cultura se fundiram em uma mesma e única forma de vida coletiva" (p. 135).

À direita ou à esquerda, os resultados dessa resistência mostraramse, contudo, melancólicos, quando se observou o triunfo da burocracia e da disciplina sobre artistas que almejavam construir novos estilos e experiências de vida (caso soviético) ou foram esmagados pelo poderio econômico e pela ditadura do mercado nas sociedades capitalistas, que lhes facultou apenas a estetização da vida e da mercadoria. A alternativa encontrada, então, deslocouse para as frestas, para ranhuras do sistema, naqueles nichos que possam permitir novas articulações. 


\section{Urdimento}

4LEHMANN, HansTies. Prefácio a Escritura política no texto teatral. São Paulo. Perspectiva: 2009, p.XXII.

${ }^{5}$ Os trechos citados na sequência são de 0 espectador emancipado, último livro de Rancière ainda não lançado no Brasil e do qual apresentamos um trecho nesse dossiê.
Articulações estas bastante semelhantes àquelas que levaram HansThies Lehmann, o teórico do teatro pós-dramático a assinalar, no prefácio à Escritura política do texto teatral - sua última obra publicada entre nós -, à interlocução que efetivou com alguns pensadores franceses que se debruçaram sobre essa seara, entre eles Jacques Rancière. $O$ desentendimento, texto de nosso filósofo, ajudou Lehmann a pensar o teatro político e, no prefácio de sua obra, aludir:

No entendimento do autor, a escritura política não significa de imediato o mesmo que pensá-la. O político parece, para dar apenas um exemplo dessa diferença, exigir uma forma de pensar que não pode ser considerada radicalmente ligada ao material de uma linguagem no sentido da mudança teórico-linguística das ciências. Aprofundar-se sobre o material de uma linguagem própria, podendo tratar-se até de várias linguagens em uma só, deve buscar ultrapassar o pensamento político, se não se quiser reprimir o fato de que o político só pode ser pensado como o espaço de muitos (pessoas, grupos, 'pluralidades', classes, coletivos, línguas, 'culturas'), que se juntam em determinados motivos do agir e do pensar, mas de forma não idêntica. ${ }^{4}$

Tal argumento, como se pode reconhecer, havia sido anteriormente cogitado por Rancière. Nos últimos anos, ao voltar-se para o teatro, nosso filósofo aglutinará novamente muito dos pressupostos examinados em textos anteriores, especialmente em $O$ mestre ignorante. Tomando a língua, a palavra - base sobre a qual se constroem os roteiros, os textos e ações que habitam a cena - é ela reinvestida de novas potências. ${ }^{5}$

Após examinar algumas particularidades que delimitam a cena teatral no ocidente, volta-se para o papel do espectador, habitualmente tomado como passivo, inerte diante das imagens e simulacros que habitam os palcos. Muitas foram as iniciativas de homens e mulheres de teatro que tentaram abolir essa pretensa passividade, havendo mesmo quem tenha almejado eliminar o espectador, integrando-o à cena, como nas ações situacionistas (um jogo coletivo de acontecimentos) ou os espectadores do teatro do oprimido (instrumentalizados para representarem). Sobre tais propostas, postula o filósofo:

Nós não precisamos transformar espectadores em atores. Nós precisamos é reconhecer que cada espectador já é um ator em sua própria história e que cada ator é, por sua vez, espectador do mesmo tipo de história. Não precisamos transformar o ignorante em instruído ou, por mera vontade de subverter coisas, fazer do aluno ou da pessoa ignorante o mestre dos seus mestres (O espectador emancipado). 


\section{Urdimento}

A emancipação, ao contrário - um novo percurso para o ignorante e um novo enfoque para aqueles que desejam atuar para alterar a situação presente - requer outros enquadramentos para os problemas, tanto aqueles que cercam a sociedade quanto aqueles que cercam a cena. Os atores deveriam desublimar seus corpos, voltando a partilhar o que existe em comum na assembléia que o espaço teatral institui e representa ${ }^{6}$, promovendo uma horizontalidade na interlocução. Ou seja,

o teatro deveria questionar o privilégio da presença viva e trazer o palco novamente para um nível de igualdade com o ato de contar uma história ou de escrever e ler um livro. Ele deveria ser a instituição de um novo estágio de igualdade, onde os diferentes tipos de espetáculo se traduziriam uns nos outros. Em todos estes espetáculos, na verdade, a questão deveria ser ligar o que uma pessoa sabe com o que ela não sabe; deveria se tratar, ao mesmo tempo, de atores que apresentam suas habilidades e espectadores que estão tentando encontrar o que aquelas habilidades poderiam produzir em um novo contexto, entre pessoas desconhecidas. (...) Ele demanda espectadores que são interpretadores ativos, que oferecem suas próprias traduções, que se apropriam da história para eles mesmos e que, finalmente, fazem a sua própria história a partir daquela. Uma comunidade emancipada é, na verdade, uma comunidade de contadores de história e tradutores (O espectador emancipado). ${ }^{7}$

Partilha do sensível, nova aprendizagem, volta ao comum, experiência horizontal e compartilhada, dissenso artístico, inconsciente estético, política da escrita, o destino das imagens - são esses alguns temas sobre os quais Jacques Rancière dedicou-se ao longo de sua vida e sua obra, entrelaçando os fios que costuram o social e o cultural, o ético e o estético, o político e o humano. Ao voltar-se para a arte, a instituição artística e seus primórdios ontológicos, buscou reinventar aquilo que as dignifica e as torna essenciais, ainda hoje, agora.

\footnotetext{
${ }^{6} \mathrm{~A}$ noção de teatro enquanto espaço público e da atividade teatral enquanto assembléia está, também, em GUÉNOUN, Denis. A exibição das palavras, uma ideia (política) do teatro. Rio de Janeiro: Teatro do Pequeno Gesto, 2003.
}

${ }^{7} T a l v e z$ seja interessante notar, nesse passo, um contraponto à ideia de Deleuze sobre a tomada de consciência como "um devir no qual a pessoa se engaja", onde o teatro "surgirá como o que não representa nada (...) enquanto deviruniversal, operando alianças aqui ou ali conforme o caso, seguindo linhas de transformação que saltam para fora do teatro e assumem uma outra forma, ou se reconvertem em teatro para um novo salto". DELEUZE, Gilles. Sobre o teatro. Rio de Janeiro: Jorge Zahar Editor, 2010, p. 64. 